\title{
Internet of Things: A Monitoring and Control System for Rockmelon Farming
}

\author{
Hazilah Mad Kaidi ${ }^{1 *}$, Norulhusna Ahmad ${ }^{1}$, Rudzidatul Akmam Dziyauddin', \\ Norliza Mohamed ${ }^{1}$, Liza Abdul Latiff ${ }^{1}$, Sahnius Usman², Robiah Ahmad", \\ Shamsul Sarip ${ }^{1}$
}

\author{
${ }^{1}$ Razak Faculty of Technology and Informatics, Universiti Teknologi Malaysia, \\ Jalan Sultan Yahya Petra, Kuala Lumpur, 54100, MALAYSIA \\ ${ }^{2}$ PPD Space, Universiti Teknologi Malaysia, \\ Jalan Sultan Yahya Petra, Kuala Lumpur, 54100, MALAYSIA \\ *Corresponding Author
}

DOI: https://doi.org/10.30880/ijie.2020.12.06.007

Received 20 December 2020; Accepted 03 June 2020; Available online 02 July 2020

\begin{abstract}
This paper describes the internet of things application in agriculture production especially for rock melon farming. In order to boost agricultural production on a commercial basis, a more systematic approach should be developed and organized to be adopted by operators to increase production and income. This work combines fertilization and irrigation in one system under protective structures to ensure that high-quality plant production and an alternative to conventional cropping systems. In addition, the use of technology for online monitoring and control is an improvement to the system in parallel with the rapid development of information technology today. The proposed system is focusing on automation, wireless, data analytics and simplified design with minimal and scalable skid size for rock melon in the Klang valley. Other than that, a monitoring and control system were developed besides, applied Internet of Thing (IoT) platform with additional user-friendly programmable farming routine Human-machine interfacing (HMI). HMI is a software interface that is capable to conduct the systems directly via autonomous cloud control. It provides time management and contributes to a more efficient workforce. The aim to develop a monitoring and controlling system using IoT for rock melon in this study was achieved. The rock melon harvesting succeeds according to the scheduled routine and the quality of yields also satisfied.
\end{abstract}

\section{Introduction}

Many industries have now undergone significant changes from conventional farming systems to products that require high technology. This trend is due to an increase in the production and quality of food produced in the market. Applying technology in existing agricultural systems can increase agricultural production commercially to a more systematic approach. Implementation of technology can help farmers in monitoring and controlling crops without having to spend time on farms. The operators no longer need to run regularly to provide water, fertilizers and plant pesticides manually. On the contrary, farmers or operators can rely on technology to perform agricultural harvesting work automatically. At the same time, systems used in agricultural activities can reduce the potential for environmental impacts such as chemical spills and cost savings of workers. The safety and quality of plants are guaranteed where the system built with sensor technology will monitoring the growth of vegetables, control humidity and temperature, reduce pests and diseases.

Production with soil fertigation system is the latest technology which is increasingly widespread use among entrepreneurs in agriculture, where it combines fertilization and irrigation in one system under protective structures to ensure the high-quality plant production and an alternative to conventional cropping systems [1-3]. Fertigation can reduce operating costs, and this is the leading cause of its interest to many users. The use of fertigation systems significantly 
reduces water and fertilizer consumption compared with other ways [4-6]. Labour costs for operating the system is also low. The system uses automatic time control devices to ensure their effectiveness [7]. In addition, the use of technology for online monitoring and control is an improvement to the system in parallel with the rapid development of information technology today, such as the system developed in [7].

In 2014, Malaysia produced about 220,226 metric tons of melons, including watermelons [8]. The highest volume growth in melon production was recorded in 2009 and 2010 at 238,671 metric tons and 235,893 metric tons respectively. Nevertheless, the number of volumes in 2014 has slightly improved as compared to the production in 2011 until 2013. According to the survey to farmers in Perak and Selangor conducted by [9], it was reported that the production of rockmelon, in particular, was inadequate, and there was a massive demand from consumers. This finding shows that demand for melons is relatively high in Malaysia.

Hence, in this work, the development of a remote controlling and monitoring system is proposed for the fertigation method which not only can be applied on rockmelon farming, yet for chillies and indoor farming as well. In technology adoption practices, [10] reported that $22 \%$ of melon fertigation farmers in Malaysia were at their best level, while the other $78 \%$ were at a moderate level. Likewise, only $5.7 \%$ of melon conventional farmers were at their best level, whereas $94.3 \%$ were at a moderate level in technology adoption, specifically from seeds to postharvest handling. This indication has discovered that the majority of melon farmers in Malaysia are still at a moderate level in embracing technology. The study also determined that postharvest handling, fertilizer, cultivation, water management, and agronomy management practices were part of the technical indicators. Besides, pests and disease management are one of the challenges encountered by melon farmers [11-12]. Therefore, outstanding technology needs to be equipped for the improvement of melon quality as well as higher production yields.

The purpose of this system is exclusively involved in agriculture, and more specifically in the development of agricultural technology. This is in line with the government's vision and also challenge the 9th Malaysia Plan (RMK-9) in which the government welcomes private sector involvement in the development of agriculture. Smart farming that equipped with current technology helps a farmer to become a modern farmer which reduce management issue while increasing productivity [13].

\section{System Design}

The system monitoring is via wireless connection and also automated cloud control that already programmed in the panel as the proposed control system. The panel is connected with wireless fidelity (WIFI) connection. A person can access to the system panel via internet connection by using smartphone, web browser, or computers to monitor the system. The personal can manually control to turn $O N / O F F$ field devices such as pump control from the smartphone or PC. Human-machine interfacing (HMI) is a technology capable of conducting the systems directly via autonomous cloud control. It is time management and contributes to a more efficient workforce.

A system in Fig. 1 is developed based on Arduino hardware and operated with $240 \mathrm{~V}_{\mathrm{AC}}$ incoming supply which stepdown to $5 \mathrm{~V}_{\mathrm{DC}}$ built in the system panel. Once the panel been powered up, the controller will be looking up for the WIFI connection of cloud logic located in the server. Cloud Logic is a program located in the server that can be downloaded to panel if internet WIFI connection is ready within the panel. The panel is connected with WIFI connection.

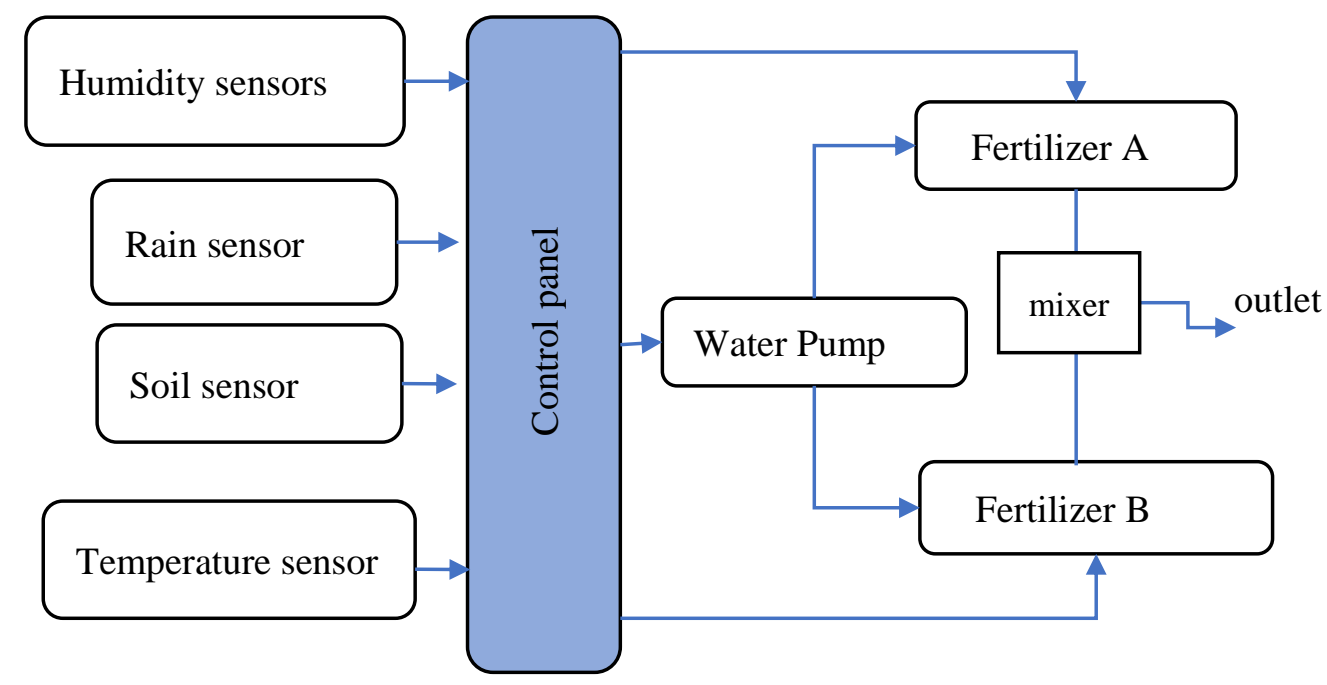

Fig. 1 - A block diagram of the proposed system 
Personnel can access the system panel via the internet connection by using smartphone, web-browser or computers to monitor the system. The personnel can manually control to turn-ON/OFF field devices such as pump control and other devices from the smartphone or PC. The microcontroller is used for developing a wireless IoT system (remote monitoring and controlling). The sensors and other devices connected in this system are described in Fig. 1. Two types of fertilizers have been connected to the control panel before it mixed in the chamber and then streamed to the plots. A rain sensor is useful for outdoor farming based on Malaysia weather. When the plants are exposed to the rain, rain and soil sensor will be activated. Based on the sensor reading, it will change the configuration setup. From this scenario, the amount of water from rain affects the reading of the soil sensor. Once the threshold of the soil sensor is triggered, the amount of water that schedule has been revised. Sometimes, it changed the watering schedule when the heavy rain affected the soil sensor reading. In this case, the humidity sensor not affected because it only measured the environment and based on the temperature sensor. All sensors mentioned are randomly put at the plant.

However, in the event of a connection failure, the system continues to run with the local logic which the controller has been program. Local logic is a downloaded logic that running in the panel. Once the program is downloaded, the panel does not require any internet connection to run the system. The program is running locally, which is isolated from any internet connection. It is an essential feature in the loss of internet connection. The downloaded cloud logic to the panel becomes a local logic which running the system.

Fig 2 shows the control panel prototype of the system. This control panel is connected via WIFI to the end-user which the mean use of IoT that applied ESP8266 and ATMega2560 micro-controller. The ESP8266 uses an AiThinker chip technology. The system has been tested for internal monitoring and controlling to the control panel. Then, it has been tested for a field and endurance test.

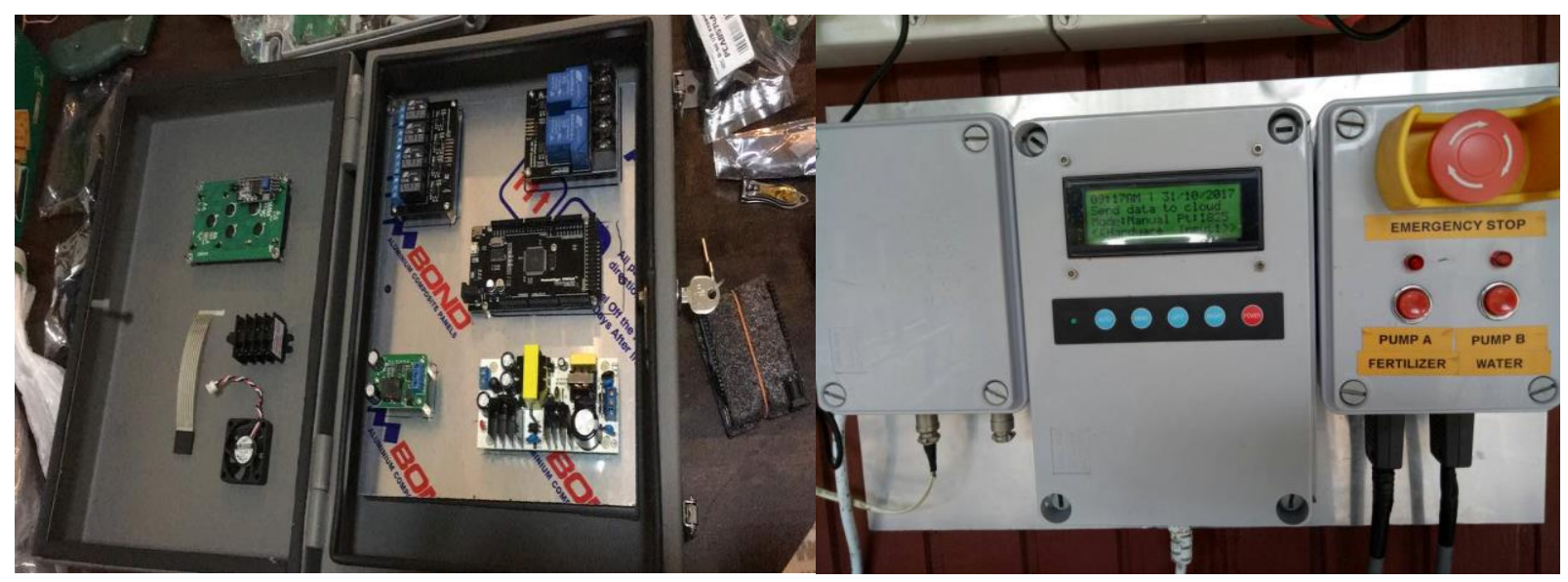

\section{Web-Based Design}

Fig. 2 - Control panel prototype of the system

This system could be tested in various fertigation systems such as for rockmelon, chilli, hydroponic plant and tomato. Moreover, the system design is purposely for rockmelon farming. Fig. 3 shows the display status of sensors, internet connection and program mode in the web-based design. The system allows a farmer to adjust the setting accordingly. In this display, we have four sensors involved which are temperature, humidity, soil moisture and rain sensor. 


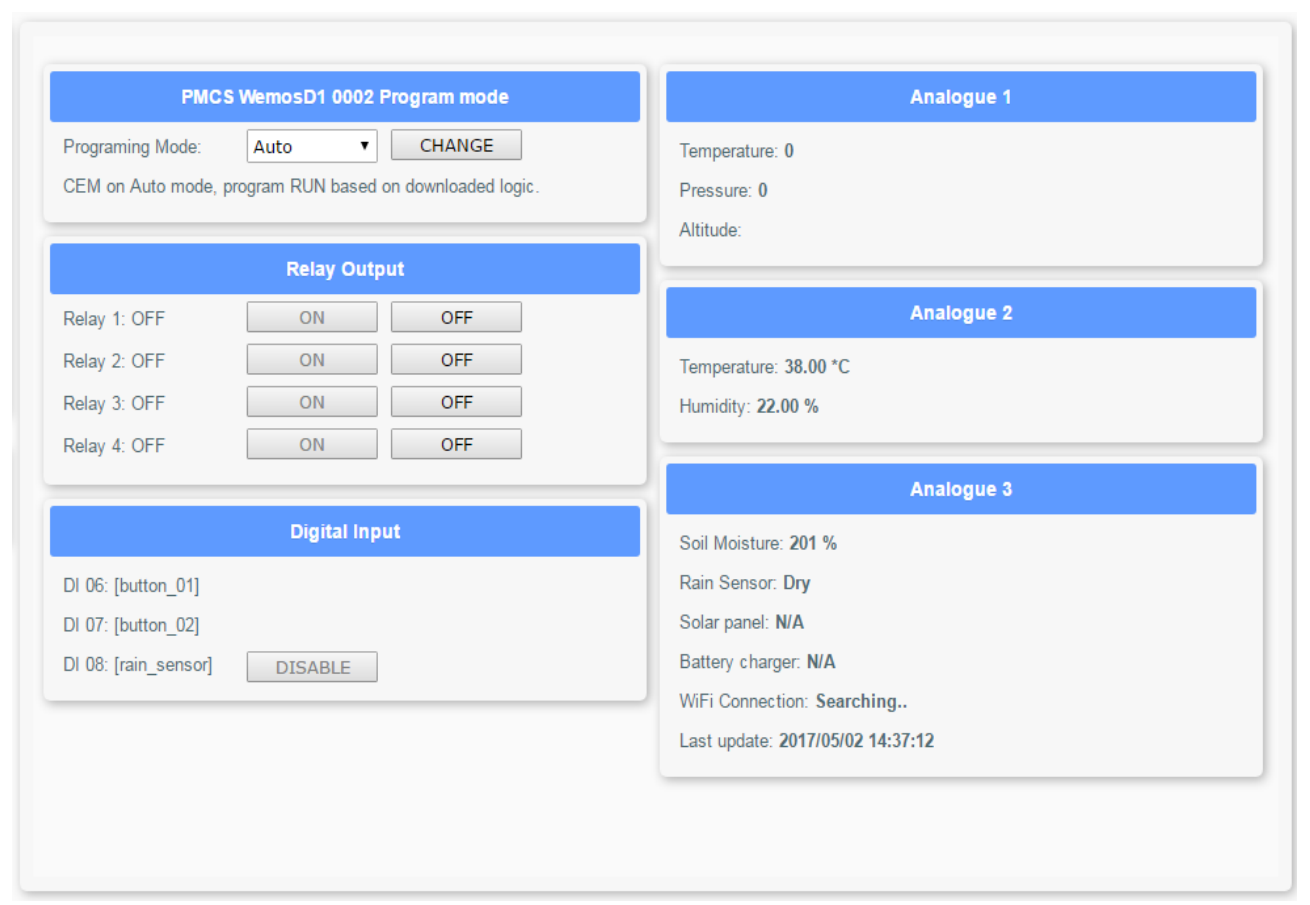

Fig. 3 - Display window in the web-based design

Fig 4 shows an example screenshot of the panel displayed on the mobile phone's view. The farmer can make simply to view the programming mode when the sensors or devices are active or inactive. This view can be improved when the mobile application is developed.

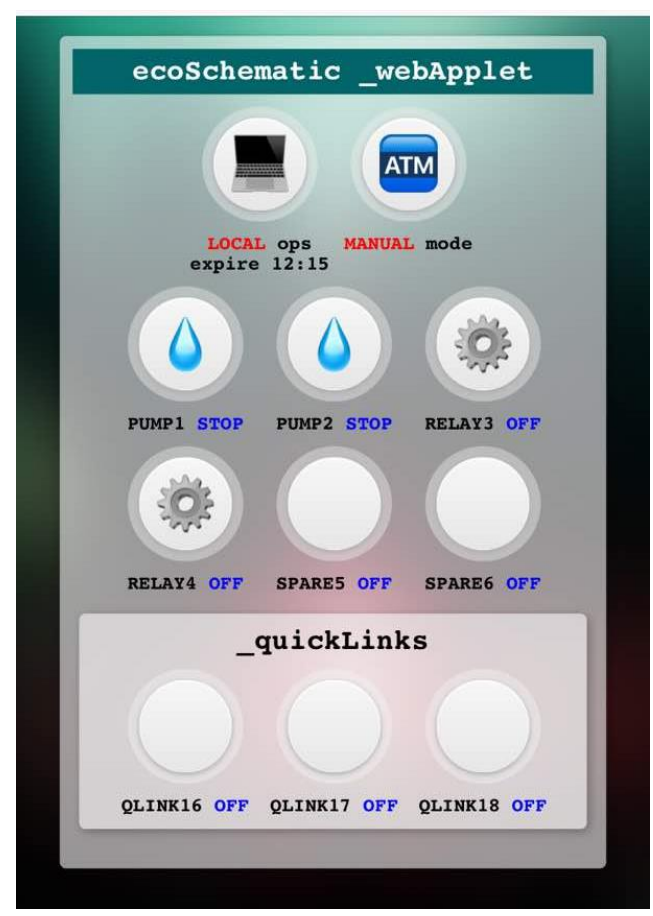

Fig. 4 - Display View in Mobile Phone

Fig 5 shows the display of a microcontroller setting for the crop. A farmer can configure this setting in both with or without an internet connection. This setting is referring to the irrigation and fertigation schedule which provided by an expert in rockmelon farming. The HMI is friendly approached by adding or editing the farming schedule 


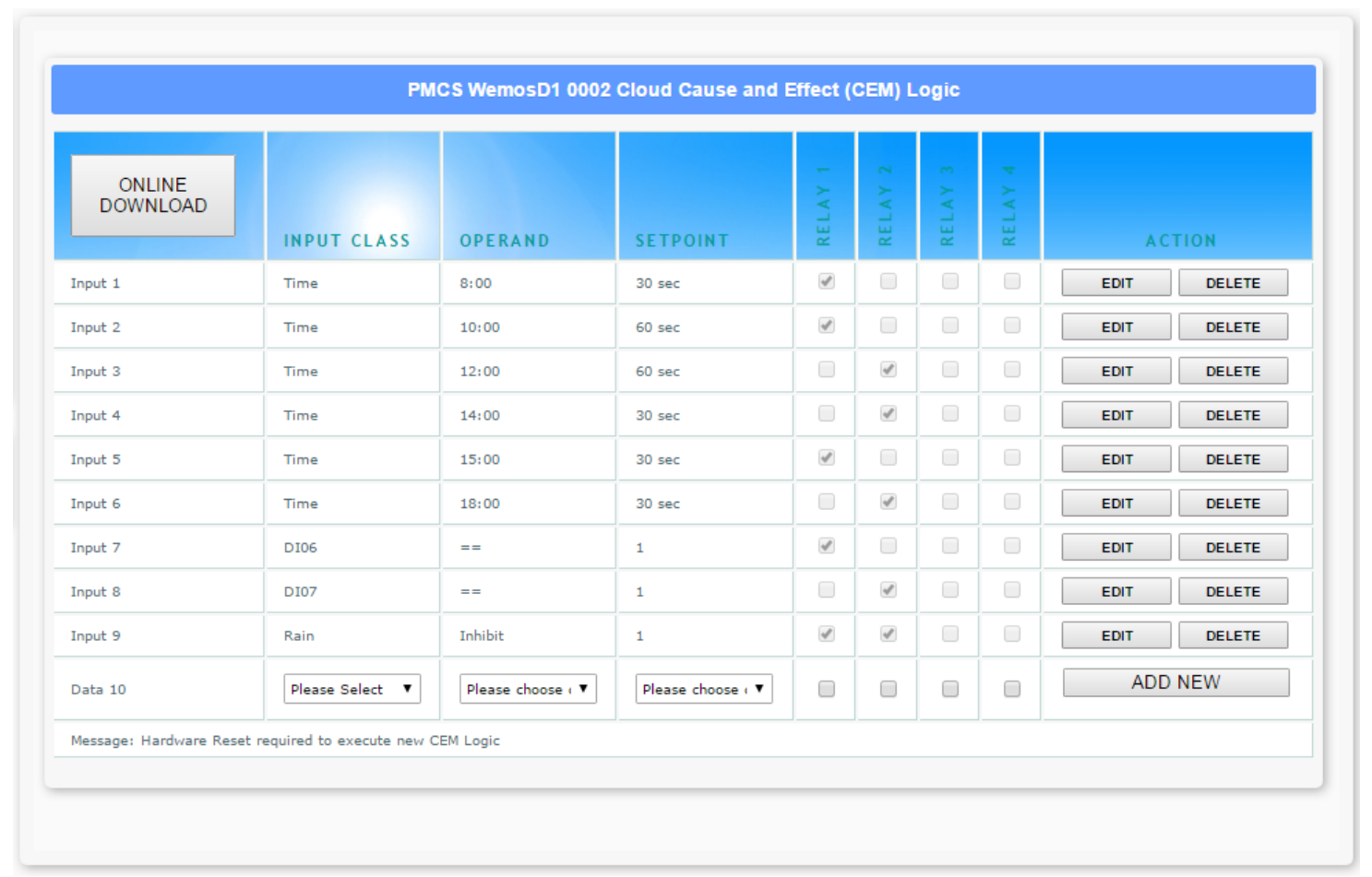

Fig. 5 - Farming Scheduling Setting

\section{Result and Discussion}

Referring to the standard of procedure (SOP) recommended by the Malaysian Agricultural Research and Development Institute (MARDI) in [14], rockmelon farming duration until harvest is approximately 80 days. For the analysis purposes, only 20 days of data have been used. For this analysis, only one variable has been analyzed, which is the temperature $\left({ }^{\circ} \mathrm{C}\right)$. In Fig 6 , it shows that the reading of the temperature sensor is within a range of $25^{\circ} \mathrm{C}-35^{\circ} \mathrm{C}$. It shows that the temperature represents Malaysia weather temperature for May-June 2018. The temperature result is consistent with the average temperature reading reported by [15], which ranged from $23^{\circ} \mathrm{C}-35^{\circ} \mathrm{C}$.

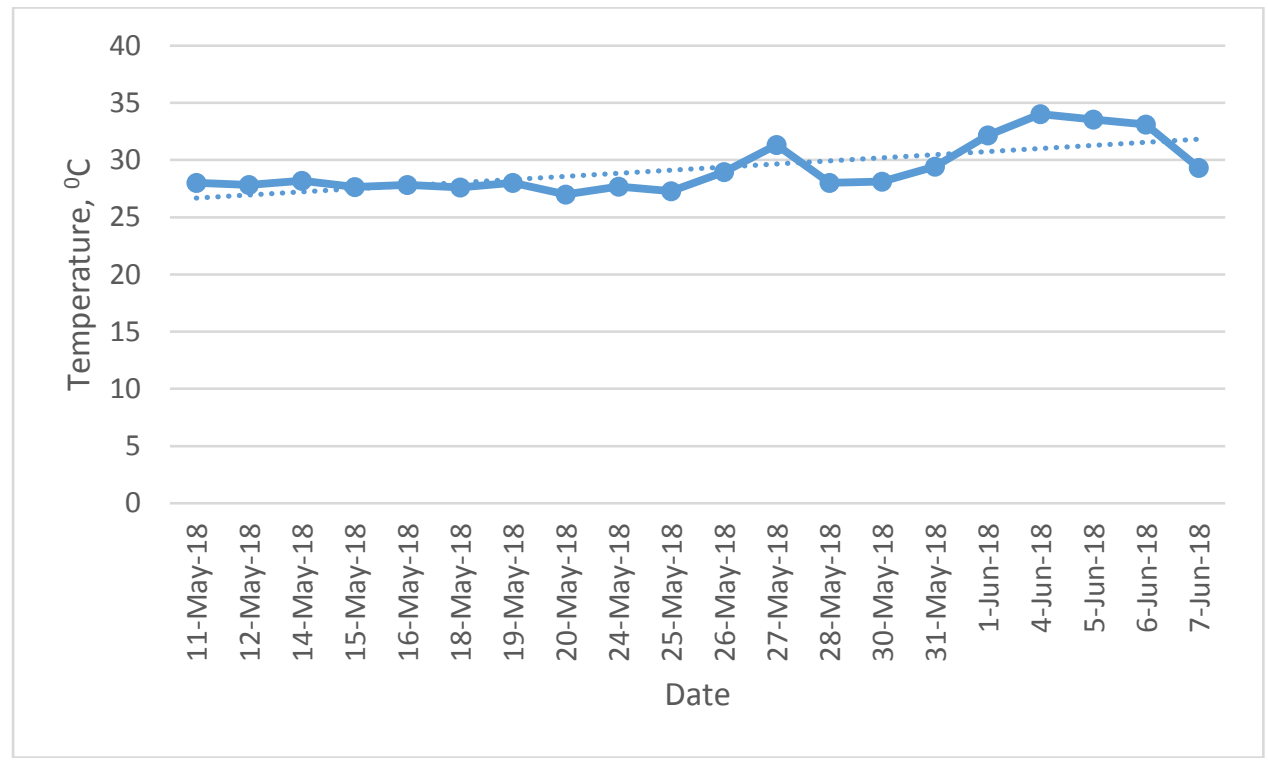

Fig. 6 - Temperature Reading of Rock Melon Farming

Fig 7 shows the process of rockmelon farming for approximately 1000 plots. It takes around 80 days to harvest the yields. This small scale project has implemented the monitoring and controlling using the proposed system with IoT technology in Klang Selangor. The weight of yield is average at $1.5 \mathrm{~kg}$. Every plant produced average at two rockmelons, 
therefore this farming has produced up to 200 rockmelons at one time. The system design can be applied in another farming environment, not only focusing on outdoor farming such as rockmelon and chilli. Cultivation in the greenhouse also suite for this proposed IoT system.

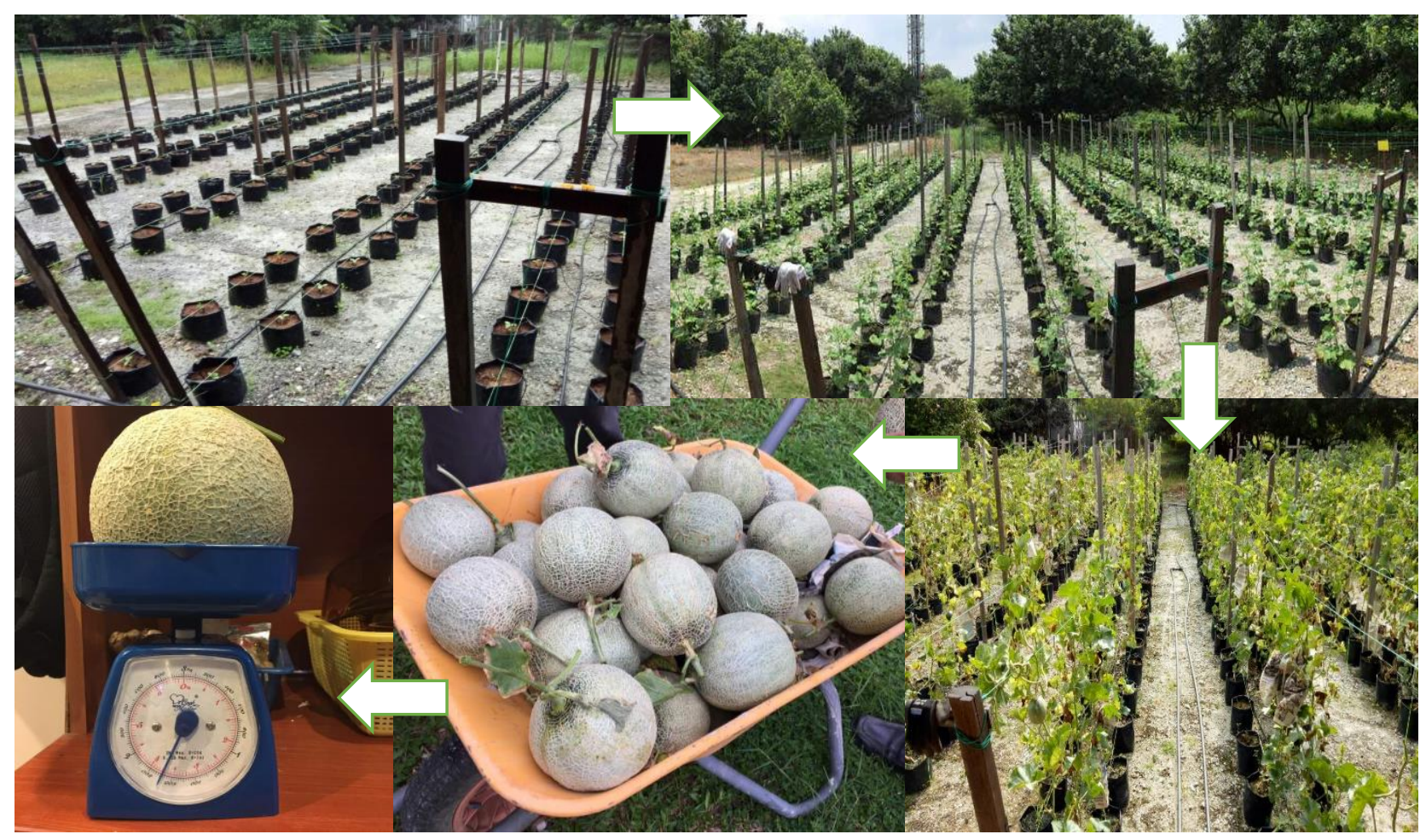

Fig. 7 - Rockmelon Farming using IoT fertigation system

\section{Conclusion}

From this research work, it found that the IoT system gave impacts to the modern farmers to involve effectively in agriculture. In current phenomena and for future trend, monitoring and controlling systems development are greatly facilitate modern farmers in monitoring their agriculture process. The IoT concept applied in modern agriculture, which can reduce some costs in the workforce, indirectly to assist farmers in managing the systematic fertilizing scheduling through the cloud. We believe that IoT system in agriculture will be tremendously increasing in Malaysia in a few years.

\section{Acknowledgement}

The authors would like to thank for the support given to this research to Universiti Teknologi Malaysia (UTM), grant Vot: Q.K130000.2540.17H58, and Q.K130000.3556.06G45, to all authors and contributors in the agriculture controlling and monitoring system development.

\section{References}

[1] Abd, S., Zainal, H., \& Ibrahim, S. N. (2015). Web-based Monitoring of an Automated Fertigation System : An IoT Application. 2015 IEEE 12th Malaysia International Conference on Communications (MICC), 1-5 https://doi.org/10.1109/MICC.2015.7725397

[2] Barradas, J. M. M., Matula, S., \& Dolezal, F. (2012). A Decision Support System-Fertigation Simulator ( DSS-FS ) for design and optimization of sprinkler and drip irrigation systems. Computers and Electronics in Agriculture, 86, 111-119. https://doi.org/10.1016/j.compag.2012.02.015

[3] José, A., Neto, S., Zolnier, S., \& Carvalho, D. De. (2014). Development and evaluation of an automated system for fertigation control in soilless tomato production, 103, 17-25. https://doi.org/10.1016/j.compag.2014.02.001

[4] Joseph, C., Thirunavuakkarasu, I., Bhaskar, A., \& Penujuru, A. (2017). Automated fertigation system for efficient utilization of fertilizer and water

[5] Mohamed, O., \& Ahmed, E. (2018). A Design of an Automated Fertigation System Using IoT. 2018 International Conference on Computer, Control, Electrical, and Electronics Engineering (ICCCEEE), 1-5 
[6] Samsuri, S. F. M., Ahmad, R., \& Hussein, M. (2010). Development of nutrient solution mixing process on timebased drip fertigation system. Asia Modelling Symposium 2010 - 4th International Conference on Mathematical Modelling and Computer Simulation

[7] S. A. H. Z. Abidin and S. N. Ibrahim, "Web-based monitoring of an automated fertigation system: An IoT application," 2015 IEEE 12th Malaysia International Conference on Communications (MICC), Kuching, 2015 , pp. $1-5$ doi: 10.1109/MICC.2015.7725397

[8] Mansor, O. (2014). Pengurusan Rantaian Bekalan Produk Agromakanan bagi Menjamin Daya Saing Industri Pertanian di Malaysia. Seminar Konsultasi Ekonomi dan Pengurusan Teknologi Pertanian (SKEP), 20th August 2014, Negeri Sembilan, Malaysia

[9] Rasmuna Mazwan, M., Mohd Syauqi, Nazmi., Mohd Zaffrie, M.A., dan Siti Zahrah, P. (2015). Kajian Menanda Aras Teknologi Pengeluaran Tembikai. Laporan Projek Sosioekonomi, Pusat Penyelidikan Ekonomi dan Sains Sosial, MARDI, Serdang

[10] Rasmuna Mazwan, M., Nik Rozana Nik Mohd Masdek, Overview of Melon Industry In Malaysia, FFTC Agricultural Policy Articles, 2016

[11] Effect of water irrigation techniques on growth and yield of rock melon (Cucumis melo Linn cv. Glamour), Hamdan, M.N ${ }^{1}$, Shafar, J.M ${ }^{2}$. Transactions of the Malaysian Society of Plant Physiology (Volume 24, No. 1, 2016, Pages 80 to 84 )

[12] Impact of Within-row Plant Spacing and Fixed Fruit Setting on Yield and Quality of Rockmelon Fruit Cultivated by Drip Irrigation in a Greenhouse [2018], Wen-Chen Wee, UCSI University, Kuala Lumpur, Malaysia Kok-Song Lai, Universiti Putra Malaysia, Serdang, Malaysia Chee-Leong Kong, Universiti Putra Malaysia, Serdang, Malaysia Wai-Sum Yap, UCSI University, Kuala Lumpur, Malaysia

[13] R. Raut, H. Varma, C. Mulla, Vijaya Rahul Pawar, Soil Monitoring, Fertigation, and Irrigation System Using IoT for Agricultural Application, Intelligent Communication and Computational Technologies pp 67-73, 2017

[14] Mahmud s, Jamaluddin S, Mohammad Roff, MN, Ab Halim AH, Mohamad AM, Suwardi AA, Manual Teknologi penanaman cili, rockmelon dan tomato secara fertigasi, MARDI Serdang (2007)

[15] https://www.timeanddate.com/weather/malaysia/shah-alam/historic?month=5\&year=2018, Malaysia's weather, Retrieved online on:20 March 2020 